\title{
Uma poética transgressora: tradução de três poemas de Lydda Franco Farías
}

\author{
Valentina Figuera Martinez \\ Diana Junkes
}

\begin{abstract}
Na tradução de poesia vige lei da compensação: vale dizer, onde um efeito não pode ser exatamente obtido pelo tradutor em seu idioma, cumpre-lhe compensá-lo com outro, no lugar onde couber (...)
\end{abstract}

Haroldo de Campos ${ }^{1}$

Resumo: Neste artigo, apresentamos a tradução comentada de três poemas de Lydda Franco Farías, poeta venęuelana cuja voz lírica destaca pelo tom questionador, intimista, irónico e burlesco dos seus versos, desafiantes da sociedade patriarcal. Os três poemas foram publicados originalmente nos livros Poemas circunstanciales (1965) e Una (1985), bem como incluídos na Antologia poética (2005) posteriormente editada da sua obra. Respaldadas nas propostas de Haroldo de Campos sobre tradução, labor que demanda uma constante tensão, desconstrução, invenção, reinvenção e reposição de signos do texto original, nos propusemos preservar os recursos literários de cada poema, não deixando de adaptar alguns elementos para dar sentido em português ao eu lírico da poeta.

Palavras-chave: tradução poética; transcriação; Lydda Franco Farías; feminismo.

Resumen: En el presente artículo presentamos la traducción comentada de tres poemas de Lydda Franco Farías, poeta venezolana cuya voz. lírica destaca por el tono cuestionador, intimista, irónico y burlón de sus versos, desafiantes de la sociedad patriarcal. Los tres poemas fueron publicados originalmente en los libros Poemas circunstanciales (1965) y Una (1985), así como también incluidos en la Antología poética (2005) posteriormente editada de su obra. Respaldadas en las propuestas de Haroldo de Campos sobre traducción, tarea que demanda una constante

1 CAMPOS, Haroldo de. Deus e o diabo no Fausto de Goethe. São Paulo: Perspectiva, 2005. 
tensión, deconstrucción, invención, reinvención y reposición de signos del texto original, nos propusimos preservar los recursos literarios de cada poema no sin adaptar algunos elementos para dar sentido en portugués al yo lírico de la poeta.

Palabras clave: traducción poética; transcreación; Lydda Franco Farias; feminismo.

\section{Palavras iniciais}

Lydda Franco Farías é uma poeta venezuelana nascida em 1943 em Sierra de San Luis, estado Falcón, região do interior ao noroeste da Venezuela, considerada uma das vozes mais vitais da poesia venezuelana durante o período de turbulência política da década de 1960, marcado pela violação de direitos humanos no país. Começa a escrever desde a adolescência, trabalha para o jornal La Mañana em sua cidade natal, onde vive até 1962. Um ano depois, radica-se em Maracaibo, estado Zulia, segunda cidade mais importante do país, colaborando com o jornal Panorama. Trabalha como bibliotecária na Faculdade de Ciências Econômicas e Sociais da Universidade del Zulia, e nesse momento acentua-se seu desconforto pelos acontecimentos políticos ${ }^{2}$, marcados por, repressão, tortura, desaparições, censura e subsequente surgimento da insurgência guerrilheira, em um cenário econômico pautado pela desigualdade social. Todos esses elementos serão incorporados ao seu discurso poético. Porém, apesar do caráter político de muitos dos seus poemas

no enuncian de modo directo el conflicto insurreccional. Por el contrario, podría decirse que el abordaje del asunto es siempre tangencial, como si la conciencia poética que construye el texto se resistiese a la evidencia de lo inmediato. Podría pensarse, incluso, que se trata de una forma de ocultamiento, de una clandestinidad muy apropiada para el ambiente de represión que entonces se respiraba en el país El texto juega a mostrarse ocultándose. (MANDRILLO, 2004, p. X) $)^{3}$.

2 Embora a Venezuela na década de 1960 não tivesse uma ditadura militar formalmente instaurada, como em vários dos países da América Latina, após o derrubamento do ditador Marcos Pérez Jiménez em 1958, se constituiu uma "democracia representativa" que privilegiou a alternância de poder de dois bloques políticos hegemônicos ilegalizando os partidos de esquerda e instaurando práticas similares às dos regímenes ditatoriais dos países do Cone Sul. Para ampliar mais sobre o tema, ver Fernando Coronil, El Estado mágico: Naturaleza, dinero y modernidad en Venezuela (1997).

3 não enunciam diretamente o conflito insurrecional. Pelo contrário, poder-se-ia dizer que a abordagem do assunto é sempre tangencial, como se a consciência poética que constrói o texto resistisse à evidência do contexto imediato. Poder-se-ia pensar, inclusive, que se trata de uma forma de ocultamento, de uma clandestinidade muito apropriada para o ambiente de repressão que se respirava então no país. O texto joga a mostrar-se ocultando-se (tradução de Valentina Figuera Martínez). 
A sua poesia não incorpora o imediatismo realista que caracteriza os textos de conteúdo político, mas tem um toque intimista, confessional, e se vale do humor e a ironia para construir versos iconoclastas, divertidamente questionadores, burlescos, frescos e expressivos (MANDRILLO, 2004, p. XIV). O feminismo do discurso poético de Lydda, apesar do rechaço veemente da escritora ao ser tachada de feminista, é outro elemento crucial dos seus versos, que valorizam o espírito crítico e a visão de mulher livre, aguerrida, questionando os estereótipos sociais e a sociedade patriarcal.

Trata-se também de uma poesia subversiva, mas não pela abordagem política, que se constitui como forma, mas pelo tom burlesco, provocador, rebelde e questionador dos seus versos. "Sempre lhe agradecerei por não ter sido panfletária" (HERNÁNDEZ, In: Farías, 2004, p. 116). Transcendeu a denuncia, sem abandoná-la, incorporando a confissão, o amor, o erotismo e manifestando a sua inconformidade como as imposições patriarcais.

Vestida sempre de roupas Wayuns, a etnia indígena do estado Zulia, participava de saraus onde recitava os seus poemas "clássicos", incluídos na seleção que fizemos neste artigo, a pedido do público que os demandava "como si se tratasse de uma cantante de rock" (MANDRILLO, 2004, p. XV). De sua obra, destacam-se: Poemas circunstanciales (1965), Edad de los grandes ataúdes (1977), Summarius (1985) -prosa poética -, Recordar a los dormidos (1993), Descalabros en obertura mientras ejercito mi coartada (1994), Bolero a media luz (1994) e Una (1998), lançados pelas editoras da Assembleia Legislativa do estado Falcón, da Secretaria de Cultura do estado Zulia e da Universidade del Zulia, entre outras. Em 2002, é publicada uma Antologia poética da sua obra editada pela Universidade Francisco de Miranda e o Instituto de Cultura do estado Falcón, sob a seleção e estudo crítico do poeta e pesquisador Pedro Cuartín. Falece em 2004 de um ataque cardíaco e em 2005 recebe o título de doutora honoris causa pela Universidade del Zulia.

Nos propomos traduzir três poemas, sem títulos, como a maioria dos versos da autora, publicados nos livros Poemas circunstanciales (1965), Una (1985) e também incluídos na Antologia poética publicada por Monte Ávila Editores Latinoamericana (2005). Ao realizarmos o exercício de tradução dos poemas de Lydda Franco Farías, que apresentamos a seguir, pudemos conviver com o universo cindido que ela apresenta, ao fazer uso de um vocabulário coloquial que paradoxalmente sugere significações insólitas, palavras que são parte de uma realidade e que, ao se unirem, constituem uma realidade outra, livres-prisioneiras do branco da página. A tradução exigiu a compreensão dos expedientes estéticos da autora e nos desafiou a recriá-los em português, sempre cientes de que só pela recriação, 
ou pela transcriação, como proporia Haroldo de Campos (1992), seria possível chegar aos poemas originais.

A tradução é sempre uma operação de rasura do original, no sentido que Derrida aponta em Torres de Babel (2002); é um texto outro, "um contrato de casamento com a promessa de inventar um filho" (DERRIDA, 2002), uma outra informação estética que faz crescer o original, no sentido compreendido por Walter Benjamin (2008); também é uma forma de lidar com a estranheza das línguas, uma operação que des-babeliza rebabelizando. Admitindo-se que o sentido fundamental ou original do texto de partida jamais poderá ser alcançado, a operação tradutória atuará apenas como uma rasura no original, como uma outra informação estética, mas que, por sua vez, poderá dar a ver a essência do original, algo que sua traduzibilidade deixa ver.

A tradução é um ato criativo e é uma forma (CAMPOS, 1992; BENJAMIN, 2008). Em poesia, essa operação é levada à máxima tensão, de modo que no exercício que aqui propomos a recriação dos significantes em português não apaga os significantes originais e, simultaneamente, os repropõe, a partir de um modo de estar poético que fica num entrelugar, que deixa ver. A corporalidade da escritura, o caráter isomórfico do poema e, ao mesmo tempo, a disseminação dos sentidos das palavras. Dito de outro modo, a tradução exige a leitura crítica dos poemas, o mergulho nos expedientes estéticos que ele apresenta, para poder vir à luz numa outra língua.

Como afirma Haroldo de Campos no ensaio "Da tradução como criação e como crítica", a tradução é suscetível de "uma vivissecção implacável, que lhe revolve as entranhas, para trazê-la novamente à luz num corpo linguístico diverso. Por isso mesmo a tradução é crítica”. Observemos, pois, como a leitura crítica dos poemas de Lydda Franco que realizamos se apresenta em nossas transcriações.

\section{Transgredir pela tradução: uma poética transgressora}

\section{Poemas circunstanciales (1965)}

No nací para ocupar un espacio y nada más. Ignoro cuál será mi participación.

Me tocó ser mujer y no me quejo, me tocó caer en la humedad del tiempo,

\section{Do livro Poemas circunstanciales (1965)}

Não nasci para ocupar um espaço e nada mais. Desconheço qual será o meu papel.

Me aconteceu de ser mulher e não me queixo, me aconteceu de cair na umidade do tempo, 
en la inhóspita sequedad de los caminos

pero ahí me quedo

entre escombros y desperdicios.

Destruyan mi epidermis resentida, despedacen mis sueños, mi alegría,

aniquílenme

mas no pretendan sancionarme

porque un día aparecí sobre la tierra

y tuve voz y grité

y tuve fronteras y no quise despertar sin ellas

y tuve armas y allí están

perfiladas, inmóviles, ariscas. na inóspita sequidão dos caminhos (5)

porém aí estanco

entre escombros e desperdícios.

Destruam a minha epiderme ressentida,

despedacem meus sonhos, minha alegria,

aniquilem-me (10)

mas não queiram me sancionar

porque um dia apareci sobre a terra

e tive voz e gritei

e tive fronteiras e não quis despertar sem elas

e tive armas e ali estão (15)

perfiladas, imóveis, ariscas.

O primeiro poema tem 16 versos e já desde a primeira palavra se distingue um discurso poético engajado com a causa feminina, intimista, inconformado com a sociedade patriarcal que força a mulher a "ocupar uma espaço e nada mais". Dessa forma, tomando o acaso que a fez nascer mulher, o sujeito poético feminino passa, ao longo dos versos a reivindicar seu direito à voz e ao grito. A questão premente que se coloca é a recusa a ocupar um papel traçado de antemão pelo fato de ser mulher, ou seja, mais do que nascer para ocupar um espaço ou para ter uma posição predeterminada pela sua condição feminina, conforme anunciam os versos de 1 a 3 ("No nací para ocupar un espacio y nada más/ Ignoro cuál será mi participación/ Me tocó ser mujer y no me quejo").

Na sequência, versos 4 a 10, num tom melancólico e aparentemente resignado, o eu-lírico feminino constata que está na umidade do tempo. Trata-se de uma mulher que sabe que poderá ter seus sonhos, suas alegrias destruídos, pela sua condição, pelo silenciamento a que a obrigam, que lhe resseca a pele, que a coloca na sequidão dos caminhos e que por fim a aniquilarão. Mas, a aparente resignação se desfaz a partir do verso 11, quando a resistência ao cinza e à vileza do mundo marca-se pelo discurso engajado, forte, firme, introduzido pela adversativa mas, que anuncia a luta, as armas perfiladas, ariscas, à espera do inimigo, à espreita, solidárias a esta voz que se levanta ( $y$ tuve vozy gritê):

mas no pretendan sancionarme

porque un día aparecí sobre la tierra

y tuve voz y grité 
y tuve fronteras y no quise despertar sin ellas

y tuve armas y allí están

perfiladas, inmóviles, ariscas.

$\mathrm{Na}$ tradução, procuramos manter o tom coloquial do poema, o que nem sempre é fácil, embora aparentemente possa parecer que na ausência de expedientes estéticos sofisticados a recriação em português seria favorecida. Tentamos dar oganicidade ao texto, observando a sonoridade do original e compensando-a em português sempre que necessário. No segundo verso, por exemplo, ainda que pudéssemos traduzir "ignoro" para o português, decidimos substituí-lo por "desconheço" porque consideramos que ganha sonoridade, em termos de sibilação, acompanhando os dois versos anteriores. No mesmo verso, onde poderíamos traduzir "participação", decidimos fazer uma compensação sonora colocando "papel”, palavra que está dentro do mesmo campo semântico, que cabe melhor em português. Ainda para manter o jogo paronomástico, fizemos ecoar o /k/ de sequidão em escombros, estanco, que também mantêm a sibilação.

\section{Una (1985)}

para ti soy tal vez una huera mujer

con el cabello levemente despeinado

digna de un cuadro renacentista

o de un ardiente cumplido o de un piropo

(dicho con el azar / con rebuscada elegancia)

de sobra sabes que me avergüenzo

de ese otro ser que me esquilma

y me avasalla

de repetir hasta borrarme

el gesto heredado de pálidas

enhiestas

amas de casa remotísimas

pero ciertamente hay un rótulo en la sangre

una danza del vientre

una marca rotunda

ten en cuenta muchacho de las cavernas

que he ido ganando el derecho

\section{Do livro Una (1985)}

para você eu talvez seja uma mulher vã com os cabelos levemente despenteados digna de um quadro renascentista

ou de um ardente galanteio ou de uma cantada

(dito ao acaso/ com rebuscada elegância)

de sobra você sabe que me envergonho

desse outro ser que me rebaixa

e me avassala

de repetir até me apagar

o gesto herdado de pálidas

insubmissas

donas de casa remotíssimas

mas certamente há um rótulo no sangue

uma dança do ventre

uma marca indelével

leve em consideração menino das cavernas

que fui conquistando o direito 
a perder de igual a igual el paraíso

la paciencia

a compartir la cama

el santo y seña

el mundo

fifty fifty

o no hay trato

vete acostumbrando hombre voraz

mujer no es sólo receptáculo

flor que se arranca

y herida va a doblarse en el florero

al fondo de la repisa

entre santos y candelabros y trastos de cocina

una mujer es una mujer más sus uñas

y sus dientes

lo siento caballero de brillante armadura

aquella doncella rompió el molde

creció de perder de igual para igual o paraíso

a paciência

de compartilhar a cama

a senha

o mundo

fifty fifty

ou não há acordo

vá se costumando homem voraz

mulher não é só receptáculo

flor que se arranca

e ferida curva-se no vaso

ao fundo da prateleira

entre santos e candeeiros e trastes de cozinha (30)

uma mulher é uma mulher mais as suas unhas

e os seus dentes

sinto muito cavaleiro de brilhante armadura

aquela donzela rompeu os moldes

cresceu

O segundo poema, um dos mais populares da autora, mantém o engajamento com a questão do feminino tal qual o primeiro. E a mulher novamente, logo nos primeiros versos, se apresenta como um ser inteiro, em sua luta, em suas demandas, seus desejos. Marca, ainda, que historicamente conquistou seu espaço, para além daquela que era uma mulher para ser observada, desejada, galanteada, no agora do poema, vai lutar, perder o paraíso, compartilhar a cama, fifty fifity. Ela rompe os moldes e se afirma em seu feminino, não se submetendo ao homem, ao cavaleiro de armadura ("lo siento caballero de brillante armadura/ aquella doncella rompió el molde/ crecio’').

O tom desse poema, sua coloquialidade, sua necessidade de comunicação autorizaram uma tradução mais literal, ainda assim recriação, já que as imagens, ainda que comuns ao universo feminino de um modo geral, por sua sonoridade têm um efeito na língua de partida e outro na língua de chegada. Sobre a comunicação poética, é preciso lembrar aqui da explicação de João Alexandre Barbosa (1974), a propósito de João Cabral de Melo Neto. É na tensão, segundo ele, entre a composição poética e a comunicação poética que o poema se situa. Na primeira perspectiva, o poema é intransitivo, os expedientes, a metalinguagem tornam a 
comunicação poética mais agreste. É na segunda perspectiva, na perspectiva da comunicação poética que se situa a poesia de Lydda Franco. Voltada para a transitividade, para a abertura aos sentidos que o discurso poético engendra, marcando-se pela experiência, pela confissão, pelo intimismo.

O poema também apresenta recursos expressivos que tentamos respeitá-los, como é o caso das metáforas "rótulo no sangue" e "despedacem meus sonhos, minha alegria". O quarto verso consideramos que ganhou sonoridade em português quando traduzimos "cantada" por "piropo". Em português perde a sonoridade do "p", mas adquiriu o som final do "a" que coincide com os "a" finais nos versos prévio e seguinte: "digna de um quadro renascentista/ou de um ardente galanteio ou de uma cantada/(dito ao acaso/ com rebuscada elegância)". Observamos também que em português o poema ganhou uma aliteração quando traduzimos "florero" por "vaso", predominando o som do "v" nos versos subsequentes e posteriores: "vai se costumando homem voraz/mulher não é só receptáculo/flor que se arranca/e ferida vai se curvar no vaso". Esse recurso expressivo não está presente na versão em espanhol.

\section{Una (1985)}

¿estás oyendo cama el edicto de mi pereza? voy a desayunarme la claraboya de la mañana voy a atragantarme periódico con tus crónicas violentas

voy a tener noticias del mundo hasta la ingesta de par en par ventanas

muéstrenme lo que sin mí despierta sacúdete ropa inmunda los dobleces espanta con lejías la penumbra soliviántate plancha aplasta en un desliz las pérfidas arrugas a volar escoba sin bruja que respire el polvo dancen muebles al ritmo que los aviente púlete piso en redención de no empañado espejo

arde sin paz cocina del infierno tápate olla impúdica cuece a la sazón luego evapórate suenen cubiertos en estampida muda a fregarse platos les llegó su hora

\section{Do livro Una (1985)}

você está ouvindo o edito da minha preguiça, cama? vou tomar a claraboia da manhã no café vou me engasgar com o jornal e suas crônicas violentas

vou tomar conhecimento das notícias do mundo até ingerir de par em par as janelas mostrem-me o que sem mim desperta sacuda roupa imunda as dobras amassadas espante com água sanitária as manchas revolte-se ferro de passar esmague em um átimo as rugas pérfidas voe vassoura sem bruxa para respirar a poeira dancem móveis ao ritmo que eu os arremesso encere-se piso em redenção do não opaco brilho arda sem paz cozinha do inferno tampe-se panela impudica

cozinhe ao ponto de logo evaporar-se soem talheres em estampido mudo lave-se louça já chegou a sua hora 
la carta por favor

quiero probar el albedrío

niños culpables

aúllenle a la luna

no estoy de humor para lidiar con monstruos

que no amor que no

la señora hoy decidió estar indispuesta

la señora hoy decidió estar indispuesta

muy dispuesta o cardápio por favor

quero experimentar o livre arbítrio

crianças culpadas

uivem à lua

não estou com humor para lidar com monstros

não, amor, não

a senhora hoje decidiu estar indisposta

a senhora hoje decidiu estar indisposta

muito disposta

No terceiro poema persiste o engajamento com a visão essencialmente feminina, transgressora e desafiante das imposições sociais. Com tom irónico, a autora descreve o percorrer de um dia no qual decidiu se rebelar contra as cargas domésticas, sem abandonar essa intimidade que evoca conhecimento e identificação do lugar de fala. Personifica à "roupa imunda" o ferro de passar, a vassoura, as panelas, os talheres, os pratos, para que se rebelem contra aquilo que a sociedade patriarcal espera que seja feito. É um protesto, um desafogo contra essa configuração de ordem na qual a mulher é confinada a uma casa, a cuidar dos filhos e ficar num espaço de subalteridade. Trata-se de uma voz poética que denota cansaço da posição passiva, mas que se dá o direito a romper progressivamente com esse esquema, a experimentar o "livre arbítrio", como aponta no verso 20. A poeta repete duas vezes "la señora hoy decidió estar indispuesta" para enfatizar que não será mais um elemento opaco, submisso e relegado, porém, no verso final recolhe as suas palavras e se declara disposta, num tom resignado, mas evoca a sensação de ter se liberado.

Para a tradução, conservamos as personificações que a poeta fez em "sacuda roupa imunda as dobras amassadas (...) revolte-se ferro de passar (...) arda sem paz cozinha do inferno/tampe-se panela impudica", bem como o tom irónico e a oralidade caraterístico da autora. De modo geral, a tipografia do original foi mantida, assim como as opções para palavras iniciadas por letras maiúsculas no início no transcorrer dos poemas.

\section{Referências bibliográficas}

BARBOSA, J. A. A imitação da forma. Rio de Janeiro: Duas Cidades, 1974.

BRANCO, L. C. (Org.). A tarefa do tradutor, de Walter Benjamin: quatro traduções para o português. Belo Horizonte: Fale/UFMG. 2008. 
CAMPOS, A., PIGNATARI, D. e CAMPOS, H. Teoria da Poesia Concreta, textos criticos e manifestos 1950-1960. Livraria Duas Cidades: $19752^{\mathrm{a}}$. ed.

CAMPOS, H. "Da Tradução como Criação e como Crítica”. In: Metalinguagem e outras metas. Perspectiva: São Paulo, $19924^{\text {a }}$ ed. p. 31-48.

DERRIDA, J. Torres de babel. Belo Horizonte: UFMG. 2003.

FARÍAS, L. F. Antología poética. Caracas: Monte Ávila Editores Latinoamericana. 2005. pp. 3, 33-34, 39-40.

LARANJEIRA, M. Poética da tradução. São Paulo: Edusp/Fapesp. 2003.

MANDRILLO, C. "Prólogo". In: Franco Farías, L. Antología poética. Caracas: Monte Ávila Editores Latinoamericana. 2005. pp. IX-XV. 